\title{
Variable temporal relationships between environment and recruitment in coral reef fishes
}

\author{
Henri Vallès ${ }^{1, *}$, Wayne Hunte ${ }^{2}$, Donald L. Kramer ${ }^{1}$ \\ ${ }^{1}$ Department of Biology, McGill University, 1205 Avenue Docteur Penfield, Montreal, Quebec H3A 1B1, Canada \\ ${ }^{2}$ Department of Biological and Chemical Sciences, University of the West Indies, Cave Hill Campus, University Drive, \\ Cave Hill, St. Michael, Barbados
}

\begin{abstract}
Studies of coral reef fish recruitment have focused more on factors influencing the return of larvae to reefs and the process of settlement than on factors affecting survival in the plankton, despite the well-documented importance of the larval environment for temperate marine species. We examined the ability of environmental factors to explain temporal patterns of recruitment in 8 taxa of coral reef fishes, distinguishing variables associated with settlement from those associated with the pelagic larval stage. At 10 d intervals over a 17 mo period, we collected newly settled fishes from settlement units in Barbados (West Indies). We collected concurrent data on 3 settlementassociated variables, lunar darkness, wind speed, and tidal amplitude, and 5 larval environment variables, sea-surface temperature, cloud cover, salinity, chlorophyll a concentration, and normalized water-leaving radiance at $555 \mathrm{~nm}$. The last 3 were associated with low-salinity intrusions originating in the Amazon. We used hierarchical partitioning and Mallow's $C(p)$ model selection to identify important variables for each taxon. Temporal patterns of recruitment differed among taxa of which 6 showed significant environmental correlations. Significant settlement variables included lunar darkness and tidal amplitude. Significant larval environment variables were diverse and varied in magnitude and sign across taxa. The effects of larval variables were generally strong relative to settlement variables. The temporal scale of the strongest environmental predictor differed across taxa. Our study supports the views that planktonic factors affecting larval survival substantially influence recruitment in coral reef fishes and that different species are affected differently by a common, temporally variable, planktonic environment.
\end{abstract}

KEY WORDS: Settlement $\cdot$ SMURF $\cdot$ Rubble $\cdot$ Pomacentridae $\cdot$ Labridae $\cdot$ Serranidae $\cdot$ Scaridae Gobiidae

Resale or republication not permitted without written consent of the publisher

\section{INTRODUCTION}

It has long been recognized that the replenishment of marine fish populations through the arrival of young individuals can be strongly influenced by planktonic processes that increase larval mortality or larval advection away from the source populations (Hjort 1914). Unlike the pelagic fishes and the demersal species associated with soft substrates that are the focus of most temperate fisheries, coral reef fishes depend on the return of pelagic larvae to adult habitat that is discrete and rare (Leis \& McCormick 2002). This challenge has fueled interest in factors influencing larval return to the reefs (Cowen \& Sponaugle 1997) and has stimulated numerous studies of larval transport and distribution (reviews in Leis 1991, Cowen 2002).

Substantial attention has been given to physical processes and environmental cues influencing larval movement to the reefs immediately before settlement (hereafter, settlement environmental variables, SEV). Many of these processes vary over fine temporal scales. They include tidal amplitude (Lozano \& Zapata 2003), tidally induced fronts (Kingsford et al. 1991), wind stress (Milicich 1994), wind-associated episodic events such as storms (Shenker et al. 1993) and the diel (Kingsford 2001) and lunar cycles (Robertson 1992). 
Less attention has been given to factors influencing survivorship of coral reef fishes throughout the pelagic larval duration (hereafter, larval environmental variables, LEV), which have been a prominent focus of fisheries research in temperate marine systems (Anderson 1988, Heath 1992, Leggett \& Deblois 1994). Studies on temperate species suggest that relevant LEV would include physical and chemical aspects of the larval environment (e.g. temperature and salinity; Fukuhara 1990, Watanabe et al. 1999), food availability (e.g. Beaugrand et al. 2003 and references therein) and predation (review in Bailey \& Houde 1989). For coral reef fishes, experimental studies show that small changes in water temperature have important effects on larval traits, such as larval duration, swimming and growth (Green \& Fisher 2004). These are traits likely to affect larval survival in the field (Houde 1987, Anderson 1988). Field studies of coral reef fishes have found positive associations between temperature and larval growth (McCormick \& Molony 1995, Wilson \& Meekan 2002, Meekan et al. 2003, Sponaugle et al. 2006), between larval growth and larval supply or recruitment (Bergenius et al. 2002, Wilson \& Meekan 2002, Meekan et al. 2003), and between temperature averaged over all, or part of, the larval duration and recruitment (Wilson \& Meekan 2001, 2002). Solar radiation and rainfall, averaged over the larval duration, can also correlate with recruitment (e.g. Acanthurus chirurgus in Panama; Bergenius et al. 2005). Nevertheless, the importance of different LEV and, in particular, the relative importance of LEV and SEV for coral reef fishes is poorly known because of the limited taxonomic and geographical scope of previous studies and because only 1 study (Wilson \& Meekan 2001) has explicitly attempted to compare SEV and LEV.

Given the differences among coral reef fishes in larval traits such as pelagic larval duration (e.g. Sponaugle \& Cowen 1997) and swimming capabilities (Fisher et al. 2005), the relative importance of SEV and LEV may differ among taxa in the same environment. In a year-long study of recruitment on the west coast of Barbados (West Indies), we found strong differences in temporal patterns among 8 co-occurring taxa, representing 5 families of coral reef fishes (Vallès et al. 2008). Differences in recruitment patterns could result from different effects of various SEV and LEV across taxa. This underscores the need to examine multiple taxa to obtain a comprehensive view. The present study investigates associations between the environment, including both SEV and LEV, and temporal patterns in recruitment for the 8 coral reef fishes examined by Vallès et al. (2008). Here, our goals are (1) to identify SEV and LEV associated with the recruitment of each taxon, (2) to assess the consistency of these associations across taxa, and (3) to examine the relative importance of SEV and LEV.

Barbados is an ideal location to investigate the role of the pelagic environment on settlement variability for co-occurring taxa because it is a predominantly selfrecruiting island (Cowen \& Castro 1994, Cowen et al. 2006). Therefore, concurrently settling taxa are likely to have experienced the same island-scale environment. Moreover, Barbados differs from most other locations in the Caribbean in that it is in the direct pathway of North Brazil Current (NBC) rings originating from Amazon River discharge (Goni \& Johns 2001). These rings are up to $400 \mathrm{~km}$ in diameter and are formed of low-salinity water that carries pigments and sediments (Muller-Karger et al. 1988, Kelly et al. 2000, Fratantoni \& Glickson 2002). Only 1 set of concurrent studies, focusing on a single species, has specifically examined the impact of these rings on fish recruitment to the west coast of Barbados (Cowen et al. 2003, Sponaugle \& Pinkard 2004a,b).

In the present study, we simultaneously investigated the role of $3 \mathrm{SEV}$, i.e. the lunar darkness cycle, the tidal amplitude cycle, and wind speed, and of $5 \mathrm{LEV}$, i.e. seasurface temperature, cloud cover (as index of light intensity), salinity, chlorophyll a concentration and normalized water-leaving radiance at $555 \mathrm{~nm}$, hereafter $\mathrm{nLw}(555 \mathrm{~nm}$ ) (as an index of suspended solids in the water column; Novo et al. 1989, Otero \& Siegel 2004). The latter 3 variables indicated the passage of NBC rings.

\section{MATERIALS AND METHODS}

Recruitment data. We monitored recruitment onto 8 standard monitoring units of recruitment of fishes (SMURFs) to coral rubble (Vallès et al. 2006) in each of 5 sites located $\geq 2 \mathrm{~km}$ apart over a $15 \mathrm{~km}$ stretch comprising most of the west (leeward) coast of Barbados (Vallès et al. 2008). These SMURFs provide a standard settlement habitat $(13 \mathrm{~cm}$ height $\times 60 \mathrm{~cm}$ diameter; approximately $0.3 \mathrm{~m}^{2}$ in surface area) consisting of a thick, physically complex layer of rubble with small crevices and holes. Predator-exclusion experiments indicate low rates of predation of recently settled fishes by larger fishes inside these units (Vallès et al. 2006). The rubble is held above a mesh bag inside a hard plastic container, allowing for rapid underwater collection without the need for visual detection of recruits by the divers (for details, see Vallès et al. 2006).

We sampled the units at all sites within $36 \mathrm{~h}$, at approximately $10 \mathrm{~d}$ intervals for a year, from 14 September 2003 to 19 September 2004, resulting in 36 sampling intervals (for details, see Vallès et al. 2008). In addition, at the southernmost site, we also obtained 9 samples immediately before (29 June to 4 September 
2003) and 7 samples immediately after (29 September to 25 November 2004) the 5 site samples. For this latter site, therefore, monitoring took place uninterruptedly for 52 consecutive $10 \mathrm{~d}$ periods (ca. $17 \mathrm{mo}$, sampling frequency: mean $\pm \mathrm{SE}=10.2 \pm 0.1 \mathrm{~d}$, mode $=10$, range $=8$ to $12 \mathrm{~d}$ depending on sea conditions). After each collection, SMURF samples were brought to the laboratory where fish specimens were identified to the lowest possible taxonomic level. Here we focus on the 8 most abundant taxa collected, including 1 pomacentrid Stegastes partitus, 1 labrid Thalassoma bifasciatum, 1 serranid Pseudogramma gregoryi, 2 scarids Sparisoma spp. and Scarus spp., and 3 gobiids Coryphopterus spp., Gnatholepis thompsoni and Lythrypnus nesiotes (see Table 1 for additional taxonomic details).

We estimated recruitment during each interval as the average number of recruits per SMURF. During the period in which 5 sites were monitored, we pooled data for each taxon across all sites, i.e. (total number of recruits for all sites combined)/(total number of SMURFs sampled at all sites combined), because recruitment of each taxon was synchronous across the 5 sites (Vallès et al. 2008). This taxon-specific synchrony in temporal patterns across sites indicated that the patterns described were unlikely to have been driven by potentially imprecise recruitment estimates or by local postsettlement processes; instead, it strongly suggested that our sampling methods were mainly capturing an underlying coast-wide temporal pattern of settlement for each taxon (Vallès et al. 2008). Unusually rough sea conditions caused the loss or burial of SMURFs at all sites on 27 December 2003 and on 6 September 2004,

Table 1. Abundance of 8 taxa recorded over a 17 mo time series (52 sampling intervals, from 29 June 2003 to 25 November 2004). Taxa are listed in order of total number of specimens recorded. Also shown is the average number of specimens recorded per standard monitoring unit of recruitment of fishes (SMURF) sample ( \pm standard error, SE) and the size criteria (maximum standard length) used to categorize specimens as newly settled. Based on local juvenile/adult abundance, Sparisoma spp. is most likely $S$. viride and/or $S$. aurofrenatum and Scarus spp. is most likely $S$. croicensis and/or $S$. taeniopterus (H. Vallès unpubl. data). Based on DNA analysis, Coryphopterus spp. includes C. glaucofraenum and C. dicrus, the

2 most abundant Coryphopterus species at our sites (H. Vallès pers. obs)

\begin{tabular}{|llrrr|}
\hline Taxon & Family & $\begin{array}{c}\text { Number of } \\
\text { specimens }\end{array}$ & $\begin{array}{c}\text { Average } \\
\text { per } \\
\text { SMURF } \pm \text { SE }\end{array}$ & $\begin{array}{c}\text { Size } \\
\text { criterion }\end{array}$ \\
\hline Sparisoma spp. & Scaridae & 1188 & $0.86 \pm 0.04$ & $<10 \mathrm{~mm}$ \\
Stegastes partitus & Pomacentridae & 1168 & $0.84 \pm 0.05$ & $<15 \mathrm{~mm}$ \\
Pseudogramma gregoryi & Serranidae & 560 & $0.40 \pm 0.03$ & $<12 \mathrm{~mm}$ \\
Lythrypnus nesiotes & Gobiidae & 293 & $0.21 \pm 0.02$ & $<10 \mathrm{~mm}$ \\
Coryphopterus spp. & Gobiidae & 225 & $0.16 \pm 0.01$ & $<10 \mathrm{~mm}$ \\
Scarus spp. & Scaridae & 168 & $0.12 \pm 0.01$ & $<10 \mathrm{~mm}$ \\
Thalassoma bifasciatum & Labridae & 120 & $0.09 \pm 0.02$ & $<12 \mathrm{~mm}$ \\
Gnatholepis thompsoni & Gobiidae & 109 & $0.08 \pm 0.01$ & $<10 \mathrm{~mm}$ \\
Total & & 3831 & $0.35 \pm 0.03$ & \\
\hline
\end{tabular}

resulting in missing data for 2 intervals. Thus, the temporal series for each taxon spanned 52 consecutive intervals, with values for only 50 intervals.

Environmental data. To investigate associations bedaily estimates over the actual number of days entailed in the $10 \mathrm{~d}$ interval preceding the sampling date of interest. We gathered the original data on the different environmental variables from a variety of sources and with different temporal and spatial resolution.

We obtained values for daily lunar darkness and thogonal) lunar variables, i.e a new moon index and a third quarter moon index. For the new moon index, we gave the days corresponding to the new moon and full moon values of 1 and 0 , respectively. We estimated the for the remaining days by linear interpolation high and low tides. We also obtained data on wind speed and cloud cover (a single daily measurement at 08:00 h local sidereal time) from the Caribbean Center of Hydrology and Meteorology. We did not use data on wind direction because wind direction (predominantly northeasterly) changed little throughout our study. For all the above environmental variables, we averaged the daily estimates over the periods corresponding to our $10 \mathrm{~d}$ intervals. Note that $10 \mathrm{~d}$ averaging reduces resolution in the semi-lunar variability in tidal amplitude (Fig. 1).

We obtained data on chlorophyll a concentration and $\mathrm{nLw}(555 \mathrm{~nm})$ using sea-viewing wide field-of-view sensor (SeaWiFs) satellite-derived estimates (http://oceancolor.gsfc.nasa.gov/ftp.html). These sea-surface data, as made available by SeaWiFs, had been averaged temporally over $8 \mathrm{~d}$ intervals and exhibited a spatial resolution of $9 \times 9 \mathrm{~km}$ bins. For each 8 d interval, we first averaged the sea-surface data spatially inside a square containing Barbados (latitude: ca. 12.8 to $13.7^{\circ} \mathrm{N}$, longitude: ca. 60 to $59.2^{\circ} \mathrm{W}$ ). We then used linear interpolation to obtain daily estimates within 


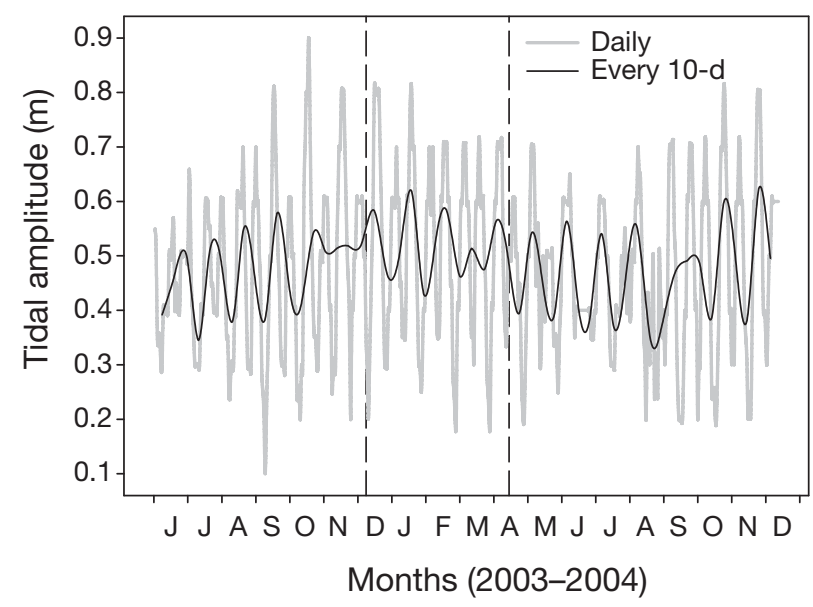

Fig. 1. Time series of tidal amplitude showing daily estimates and the derived $10 \mathrm{~d}$ estimates corresponding to the 52 consecutive sampling intervals spanning the period of the study. Note loss of temporal resolution in the $10 \mathrm{~d}$ estimates. The period between vertical dashed lines corresponds to the dry season (mid-December to mid-April)

these $8 \mathrm{~d}$ intervals, and finally averaged these daily estimates over the periods corresponding to our $10 \mathrm{~d}$ intervals.

We obtained data on sea-surface temperature and salinity by frequently ( 1 to 7 times per $10 \mathrm{~d}$ period, depending on sea conditions) taking measurements at a central site $1.5 \mathrm{~km}$ off the west coast $\left(13^{\circ} 11^{\prime} 00.5^{\prime \prime} \mathrm{N}, 59^{\circ} 38^{\prime} 44.2^{\prime \prime} \mathrm{W}\right)$ at a depth of $8 \mathrm{~m}$. These measurements were averaged over the $10 \mathrm{~d}$ sampling intervals. Due to equipment failure, we lacked field measurements for the final 7 sampling periods. For salinity, we were not able to estimate these missing periods using other sources. For temperature, we estimated missing values using satellite-derived data from the moderate resolution imaging spectroradiometer (MODIS) (http://poet. jpl.nasa.gov/) processed in a manner similar to that described for chlorophyll $a$ and nLw(555 nm) (details in Vallès 2008). Because the field and satellite-derived temperatures were highly correlated over the $10 \mathrm{~d}$ intervals for which we had both $(\mathrm{r}=$ 0.927, $\mathrm{n}=45$ ), we predicted the missing field values from the satellite data using linear regression.

Data analysis. Recruitment and environmental series: To assess whether temporal patterns of recruitment over the 17 mo period differed across taxa, we compared patterns (1) visually, by examining the timing of intervals of high recruitment for each taxon, which we arbitrarily defined as intervals with average catches exceeding the 75th percentile of the entire recruitment series, and (2) statistically, by performing pair-wise Pearson correlations between all taxon pairs.

To account for autocorrelation present in some of the recruitment series (see Vallès 2008), we performed the correlations between all pairs of taxa following the procedure described by Pyper \& Peterman (1998) to avoid inflated Type I errors during significance tests. Furthermore, given the large number of pair-wise comparisons, we sequentially adjusted p-values using the procedure described by Holm (1979). To examine associations among environmental variables, we also used the 2 analytical approaches described above. Prior to all analyses, all recruitment series were fourthroot transformed to reduce the influence of extreme values. We also fourth-root transformed chlorophyll a and $\mathrm{nLw}(555 \mathrm{~nm})$ to reduce the influence of several extreme values, and we removed a linear trend in salinity to improve stationarity (Legendre \& Legendre 1998).

Recruitment-environment associations: We examined associations between recruitment and the environment for each taxon separately. We excluded salinity from these analyses because it did not cover the entire series and because examination of the correlations among environmental variables indicated that salinity was highly correlated with chlorophyll $a$, and so was redundant (see 'Results').

To identify the most important variables associated with recruitment and assess their relative importance, we used 2 complimentary statistical approaches based on a multiple linear regression framework. We first used hierarchical partitioning (Chevan \& Sutherland 1991) to identify the environmental variables with the highest independent contributions to recruitment. For a given set of explanatory variables (i.e. environmental variables), hierarchical partitioning will quantify the improvement in fit $\left(\mathrm{r}^{2}\right)$ of all possible models of recruitment with a given environmental variable compared to the equivalent model without that variable. Then, it will average the improvement in fit across all possible models with that environmental variable. This average improvement in fit represents the contribution of each environmental variable to recruitment that can be attributed only to the environmental factor itself, i.e. independent contribution. Hierarchical partitioning does not require explicitly formulating an explanatory model, which helps alleviate problems associated with potential inter-correlations among explanatory variables (Mac Nally 1996, 2000). We used an arbitrary a priori criterion to identify the most important variables for each taxon. The expected average independent contribution of each environmental variable, if all variables are uncorrelated and contribute equally to the recruitment, would be $12.5 \%$ (100\%/8). Thus, we considered any environmental variable whose independent contribution was $>12.5 \%$ as a potentially important variable; this approach ensured consistency across taxa in the way in which we identified such variables. We used a linear regression model in the 'hier.part' 
package (Walsh \& Mac Nally 2003) implemented in the software package R (Version 1.7: www.r-project.org) to measure the independent contribution of each environmental variable.

Parallel to hierarchical partitioning, we carried out an exhaustive search of all possible linear models to retain the 'best' one, based on the Mallow's $C(p)$ statistic. The $C(p)$ statistic helps determine the adequacy of a reduced model by measuring the amount of residual variation contained in that model relative to that of the full model (Kutner et al. 2004). These analyses were performed by the 'leaps' package of the software package R (Version 2.4.1: www.r-project.org), which involved comparing the full model (all environmental variables included) with all possible reduced models (fewer environmental variables included) to retain the reduced model for which Mallow's $C(\mathrm{p})$ was lowest. This approach required explicitly formulating the model that best fit our data set, allowing us to test its statistical significance and quantify its explanatory power.

For each taxon, we considered the most important variables as those that were consistently identified by both hierarchical partitioning and the Mallow's $C(p)$ model selection (see also Mac Nally 2000). This implied retaining those variables (1) that exhibited an independent contribution that exceeded $12.5 \%$ and (2) that were also included in the best Mallow's $C(p)$ model after confirming the overall significance (at a nominal value of 0.05 ) of the model.

We assessed the overall significance of the $C(\mathrm{p})$ models through 9999 randomizations of the data using CANOCO 4.5 for Windows (ter Braak \& Smilauer 2002). For the recruitment series that did not exhibit significant serial correlation, permutations of the data were allowed without any restriction. For the recruitment series that exhibited significant serial correlation, permutations were restricted to ensure that the temporal dependency of the data was preserved (Fortin \& Dale 2005) to avoid inflated Type I errors during significance tests (for details, see Vallès 2008). Once we identified the most important variables (see above), we assessed their relative importance for each taxon by comparing their relative ranks based on the independent contributions obtained using hierarchical partitioning and on the standardized partial regression coefficients obtained from the $C(\mathrm{p})$ model.

A preliminary examination of the data indicated no strong evidence of non-linear relationships between recruitment and the 8 variables. Moreover, preliminary attempts to include interaction terms in the analyses indicated that these terms did not contribute or made only minor contributions to recruitment. Thus, for simplicity, they were not included in the final analysis. Finally, for each $C(p)$ model retained, we examined the Cook's distance measures following Kutner et al.
(2004), in order to identify single observations potentially strongly influencing the fitted regression model and its parameter estimates.

The LEV temperature, chlorophyll $a$, nLw(555 nm) and cloud cover, were assumed to operate throughout the entire larval stage. Thus, prior to these analyses, we averaged the original $10 \mathrm{~d}$ values over the estimated larval duration of each taxon relative to the time of catch. For example, for a taxon with a larval duration of 30 d (i.e. spanning 3 sampling intervals) caught at a given interval, we would average the environmental variable over the $10 \mathrm{~d}$ interval when it was caught plus the 3 preceding $10 \mathrm{~d}$ intervals.

We used several sources to estimate larval duration at the $10 \mathrm{~d}$ temporal resolution of our study. For Stegastes partitus, Thalassoma bifascitaum, Gnatholepis thompsoni and Coryphopterus spp. we used published values obtained in Barbados (Sponaugle \& Cowen 1994, 1996b, 1997). For Sparisoma spp. we used published values obtained elsewhere (Robertson et al. 2006) and confirmed by otolith examination of 5 specimens from our study (B. Victor unpubl. data). For Scarus spp., Pseudogramma gregoryi and Lythrypnus nesiotes, we used otolith examination of 3 to 6 specimens from our study (B. Victor unpubl. data). We estimated the larval duration of Sparisoma spp., G. thompsoni and P. gregoryi to span 6 sampling intervals (60 d) preceding recruitment, that of $T$. bifasciatum to span 5 sampling intervals ( $50 \mathrm{~d}$ ), and that of the 4 remaining taxa to span 3 sampling intervals (30 d).

\section{RESULTS}

\section{Recruitment series}

Recruitment over the 17 mo long series was largely dominated by Sparisoma spp. and Stegastes partitus; Thalassoma bifasciatum and Gnatholepis thompsoni were the least abundant taxa (Table 1). Most taxa recruited throughout most of the study. For Sparisoma spp., S. partitus, Pseudogramma gregoryi, Coryphopterus spp., Scarus spp. and Lythrypnus nesiotes, recruitment occurred during 68\% (Coryphopterus spp.) to $100 \%$ (Sparisoma spp.) of the sampling intervals (Fig. 2). For T. bifasciatum and G. thompsoni, recruitment took place less often, with catches in 44 and $52 \%$ of the sampling intervals, respectively (Fig. 2).

Temporal patterns of recruitment differed, and maximum recruitment occurred at different times for all taxa (Fig. 2). Furthermore, intervals of high recruitment tended to occur at different times for the different taxa (Fig. 2). For 2 pairs of taxa, Coryphopterus spp. and Scarus spp. as well as Scarus spp. and Lythrypnus nesiotes, the timing of high recruitment overlapped in 


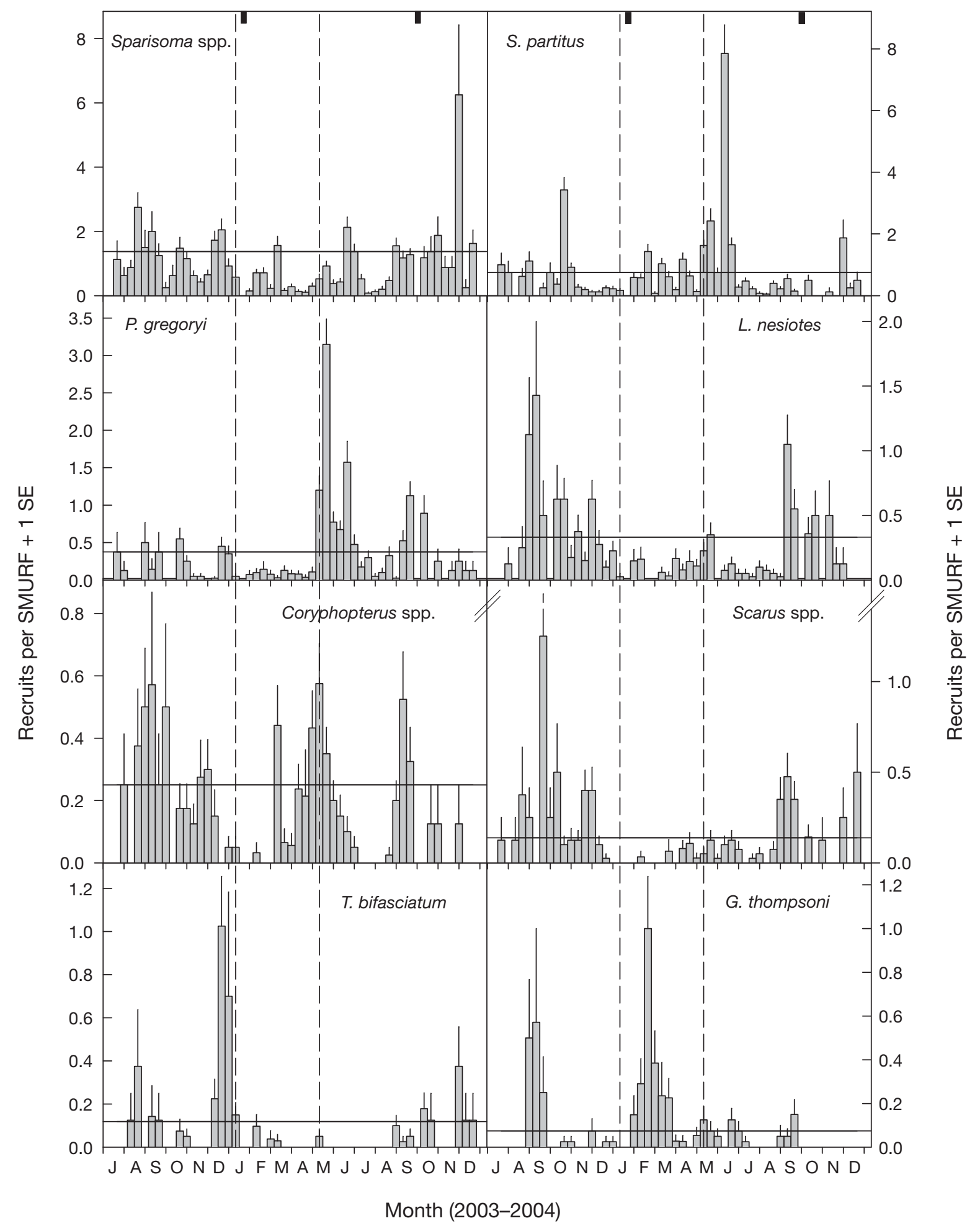

Fig. 2. Mean recruit abundance per SMURF over 52 consecutive 10 d sampling intervals (29 June 2003 to 25 November 2004 ) along the west coast of Barbados. Panels are ordered from left to right and from top to bottom by decreasing number of specimens (see Table 1 for full species names). Horizontal solid line indicates 75th percentile of the entire series, above which mean recruit abundance is considered to be high. Black top bars indicate periods with no data. The period between vertical dashed lines corresponds to the dry season (mid-December to mid-April). Note difference in ordinate scale among panels 
54 to $56 \%$ of the occasions, respectively; for the other 26 taxon pairs, the timing of high recruitment overlapped in $<50 \%$ of the occasions (Fig. 2). Temporal patterns were generally not significantly correlated. The only significant correlation was between Thalassoma bifasciatum and Sparisoma spp. ( $\mathrm{r}=0.553$, adjusted $\mathrm{p}<0.01$ ), but visual inspection of recruitment of these 2 taxa did not indicate a strong similarity in patterns (Fig. 2).

\section{Environmental series}

Visual inspection of the environmental variables revealed substantial differences in scales of variation
(Figs. 1 \& 3). Temperature exhibited variability operating predominantly over large temporal scales, with fluctuations consistent with the annual cycle. Lunar and related tidal amplitude variables exhibited predominantly fine-scale variability (Figs. 1 \& 3). Wind speed, which was generally weak ( 0.5 to $\left.3.5 \mathrm{~m} \mathrm{~s}^{-1}\right)$, and cloud cover, chlorophyll $a$, salinity and nLw(555 nm) exhibited fluctuations at both large and fine temporal scales (Fig. 3). There was evidence of temporal coherence among some of the latter variables. In particular, salinity, which exhibited relatively high values (i.e. >34.5 psu) predominantly between September 2003 and March 2004, appeared to be inversely related to chlorophyll $a$ and $\mathrm{nLw}(555 \mathrm{~nm})$, for which values were relatively low during the September 2003 to March
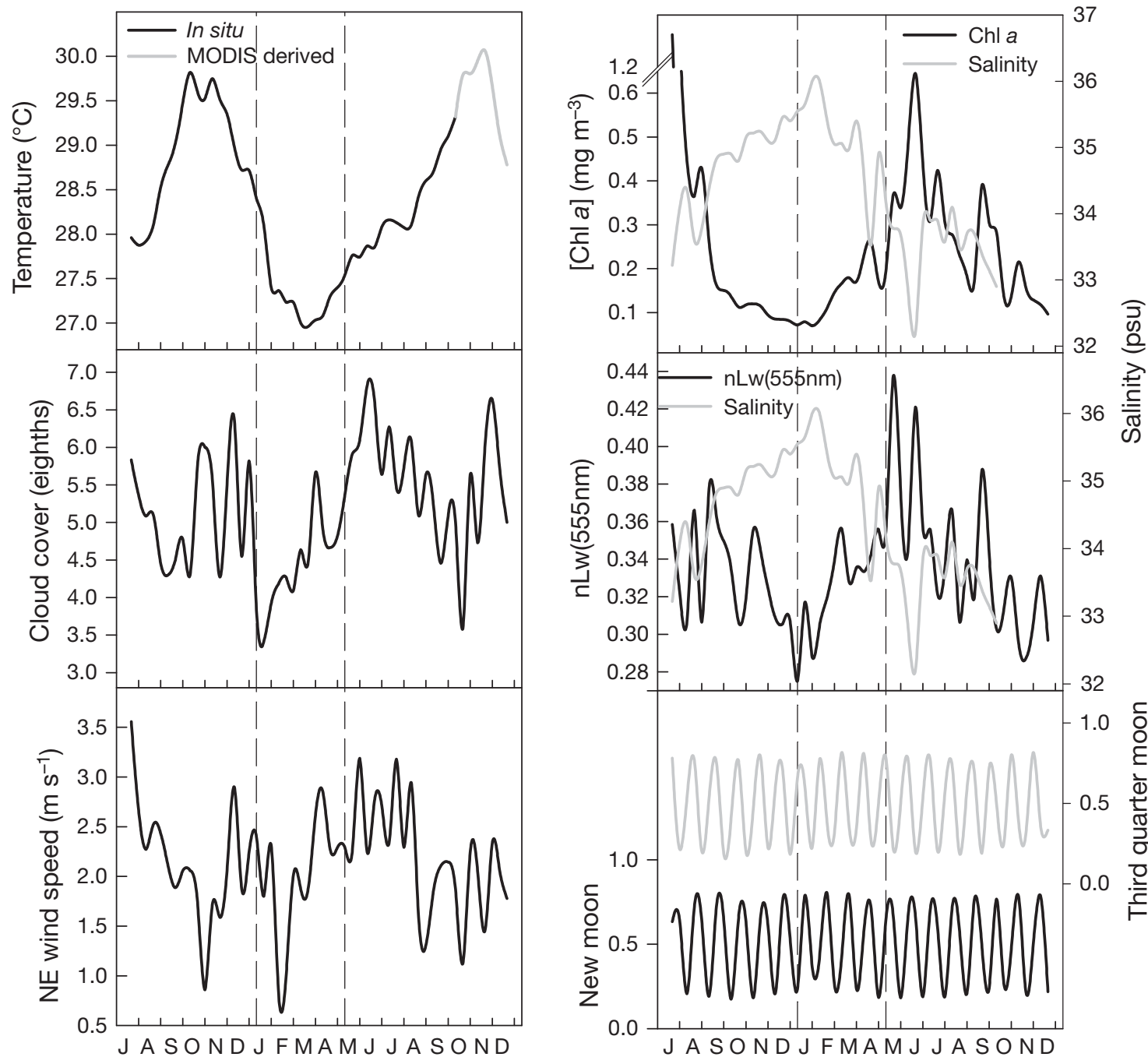

Month (2003-2004)

Fig. 3. The $10 \mathrm{~d}$ estimates of 8 environmental series corresponding to 52 consecutive sampling intervals (from 29 June 2003 to 25 November 2004). The period between the vertical dashed lines corresponds to the dry season (mid-December to mid-April). Chl a: chlorophyll a concentration; $\mathrm{nLw}(555 \mathrm{~nm})$ : water-leaving radiance at $555 \mathrm{~nm}$ 
2004 period (Fig. 3). Although chlorophyll $a$ and $\mathrm{nLw}(555 \mathrm{~nm})$ appeared to be coherent over large scales, they were less coherent over the finer scales (i.e. number and timing of pulses). In particular, both variables differed in patterns during the first few intervals of the series, when peaks in chlorophyll a were not mirrored by peaks in $\mathrm{nLw}(555 \mathrm{~nm}$ ) (Fig. 3).

Correlations among environmental variables were generally weak to moderate $(0.025 \leq|r| \leq 0.575)$. The sole exception was a very strong negative correlation between chlorophyll $a$ and salinity $(\mathrm{r}=$ -0.860 ), which was the only significant correlation after accounting for the autocorrelation present in the series and for multiple comparisons (adjusted $p=0.042$; all other correlations, adjusted $\mathrm{p} \geq 0.088$ ).

\section{Recruitment-environment associations}

Hierarchical partitioning and model selection generally agreed on the important variables for each taxon. For Pseudogramma gregoryi, Thalassoma bifasciatum and Scarus spp., the variables that exceeded the threshold criteria during hierarchical partitioning (Fig. 4) were the same variables retained in the $C(p)$ models, and these overall models were significant (Table 2). For Stegastes partitus and Gnatholepis thompsoni, the C(p) model was also significant and included all the variables identified by hierarchical partitioning. In addition, for $S$. partitus, the overall model included 2 additional variables, and, for G. thompsoni, 1 additional variable not identified by hierarchical partitioning (Fig. 4, Table 2). However, for $S$. partitus, the 2 variables (nLw[555 nm] and chlorophyll a) were very close to the threshold criteria (Fig. 4). For Sparisoma spp., all variables identified by hierarchical partitioning, except tidal amplitude, were included in the $C(\mathrm{p})$ model, which also was significant (Table 2). Tidal amplitude, however, only marginally exceeded the threshold criterion (Fig. 4). For Lythrypnus nesiotes and Coryphopterus spp., hierarchical partitioning indicated that some variables were potentially important (Fig. 4). However, for these 2 taxa the $C(\mathrm{p})$ models were not significant and explained little variation $(<10 \%$; Table 2$)$, so these taxa are not considered further. The 6 overall models that were significant

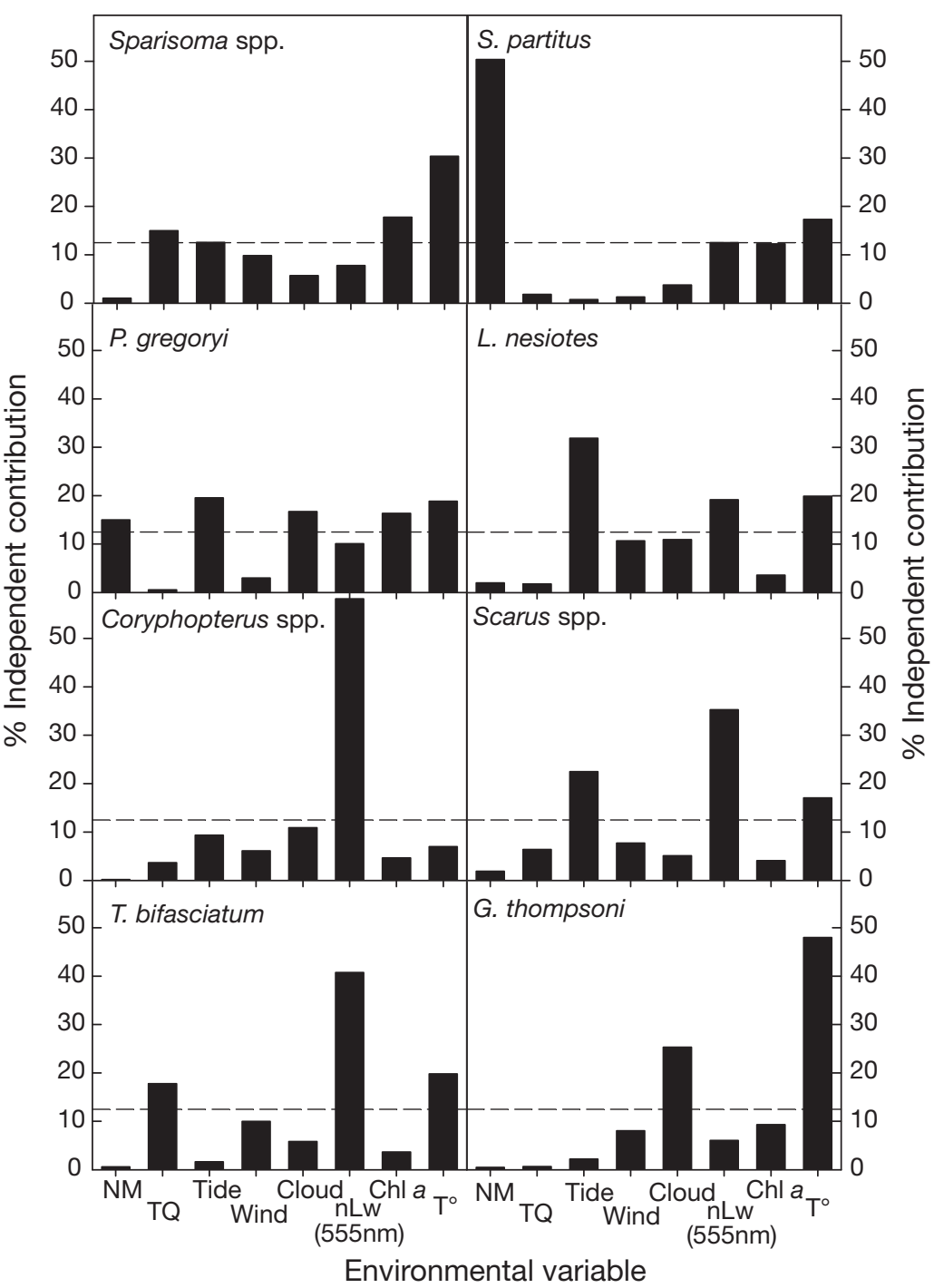

Fig. 4. Results of hierarchical partitioning showing the independent contribution of 8 environmental variables to the temporal patterns of recruitment of 8 taxa (see Table 1). Panels are ordered from top to bottom by decreasing overall numbers of specimens caught. Dashed horizontal lines demarcate threshold beyond which variables were considered to be potentially important. NM: new moon; TQ: third quarter moon; Tide: tidal amplitude; Wind: wind speed; Cloud: cloud cover; $\mathrm{nLw}(555 \mathrm{~nm})$ : normalized water-leaving radiance at $555 \mathrm{~nm}$; Chl $a$ : chlorophyll a concentration; $\mathrm{T}^{\circ}$ : sea-surface temperature

explained on average $25.4 \%$ of the total variation in recruitment (Table 2).

Overall, both SEV and LEV appeared to play an important role for most taxa, as indicated by the variables that exceed our threshold criterion during hierarchical partitioning and were also retained in the $C(\mathrm{p})$ models (Table 3). For 5 out of the 6 taxa, we found evidence of an important role of SEV associated with the lunar cycle. Stegastes partitus and Pseudogramma gregoryi were positively associated with the new moon, Sparisoma spp. and Thalassoma bifasciatum 
Table 2. Results of Mallow's $C(\mathrm{p})$ model selection for 8 taxa showing the variables retained by the best model, i.e. lowest $C(\mathrm{p})$. The Mallow's statistic, the adjusted $\mathrm{r}^{2}$ and the $\mathrm{p}$-value are shown for each model. To facilitate comparisons, bold font always indicates significant $\mathrm{p}$-values $(\mathrm{p}<0.05)$, which were obtained by randomizing the data. $\mathrm{nLw}(555 \mathrm{~nm})$ : normalized water-leaving radiance at $555 \mathrm{~nm}$

\begin{tabular}{|c|c|c|c|c|c|c|c|c|}
\hline & $\begin{array}{l}\text { Sparisoma } \\
\text { spp. }\end{array}$ & $\begin{array}{l}\text { Stegastes } \\
\text { partitus }\end{array}$ & $\begin{array}{c}\text { Pseudogramma } \\
\text { gregoryi }\end{array}$ & $\begin{array}{l}\text { Lythrypnus } \\
\text { nesiotes }\end{array}$ & $\begin{array}{l}\text { Coryphop- } \\
\text { terus spp. }\end{array}$ & $\begin{array}{l}\text { Scarus } \\
\text { spp. }\end{array}$ & $\begin{array}{l}\text { Thalassoma } \\
\text { bifasciatum }\end{array}$ & $\begin{array}{r}\text { Gnatholepis } \\
\text { thompsoni }\end{array}$ \\
\hline \multicolumn{9}{|l|}{ Overall model } \\
\hline Mallow's $C(p)$ & 4.082 & 3.355 & 3.581 & 1.446 & -1.299 & 1.185 & 1.802 & 0.984 \\
\hline Adjusted $\mathrm{r}^{2}$ & 0.247 & 0.362 & 0.226 & 0.061 & 0.080 & 0.155 & 0.239 & 0.297 \\
\hline $\mathrm{p}$-value & 0.026 & $<0.001$ & 0.010 & 0.082 & 0.117 & 0.011 & 0.018 & 0.019 \\
\hline \multicolumn{9}{|l|}{ Partial coefficients } \\
\hline New moon & - & 0.481 & 0.201 & - & - & - & - & - \\
\hline Third quarter moon & 0.265 & - & - & - & - & - & 0.258 & - \\
\hline Tidal amplitude & - & - & -0.264 & -0.291 & - & -0.205 & - & - \\
\hline Wind speed & - & - & - & -0.231 & - & - & - & - \\
\hline Cloud cover & - & 0.225 & 0.355 & - & -0.247 & - & - & -0.306 \\
\hline $\mathrm{nLw}(555 \mathrm{~nm})$ & - & 0.244 & - & - & 0.372 & 0.340 & -0.331 & - \\
\hline Chlorophyll a & 0.311 & -0.440 & -0.379 & - & - & - & - & -0.240 \\
\hline Temperature & 0.477 & -0.346 & -0.341 & - & - & 0.285 & 0.245 & -0.432 \\
\hline
\end{tabular}

Table 3. Summary of the most important variables jointly identified by hierarchical partitioning and the model selection, and the sign of their association with recruitment as inferred from the $C(p)$ model (in brackets). Right and left superscript numbers indicate rank in importance of the variable according to the hierarchical partitioning and to the $C(\mathrm{p})$ model, respectively. $\mathrm{x}$ : variables that were identified by either hierarchical partitioning or the model selection, but not by both; $\mathrm{nLw}(555 \mathrm{~nm})$ : normalized water-leaving radiance at $555 \mathrm{~nm}$

\begin{tabular}{|lcccccc|}
\hline & $\begin{array}{c}\text { Sparisoma } \\
\text { spp. }\end{array}$ & $\begin{array}{c}\text { Stegastes } \\
\text { partitus }\end{array}$ & $\begin{array}{c}\text { Pseudogramma } \\
\text { gregoryi }\end{array}$ & $\begin{array}{c}\text { Scarus } \\
\text { spp. }\end{array}$ & $\begin{array}{c}\text { Thalassoma } \\
\text { bifasciatum }\end{array}$ & $\begin{array}{c}\text { Gnatholepis } \\
\text { thompsoni }\end{array}$ \\
\hline New moon & - & ${ }^{1}(+)^{1}$ & ${ }^{5}(+)^{5}$ & - & - & - \\
Third quarter & ${ }^{3}(+)^{3}$ & - & - & - & ${ }^{3}(+)^{2}$ & - \\
Tidal amplitude & $\mathrm{x}$ & - & ${ }^{1}(-)^{4}$ & ${ }^{2}(-)^{3}$ & - & - \\
Wind speed & - & - & - & - & - & - \\
Cloud cover & - & $\mathrm{x}$ & ${ }^{3}(+)^{2}$ & - & - & ${ }^{2}(-)^{2}$ \\
nLw(555 nm) & - & $\mathrm{x}$ & - & ${ }^{2}(+)^{1}$ & ${ }^{1}(-)^{1}$ & - \\
Chlorophyll a & ${ }^{2}(+)^{2}$ & $\mathrm{x}$ & ${ }^{4}(-)^{1}$ & - & - & $\mathrm{x}$ \\
Temperature & ${ }^{1}(+)^{1}$ & ${ }^{1}(-)^{2}$ & ${ }^{2}(-)^{3}$ & ${ }^{3}(+)^{2}$ & ${ }^{2}(+)^{3}$ & ${ }^{1}(-)^{1}$ \\
\hline
\end{tabular}

were positively associated with the third quarter moon, and Scarus spp. and P. gregoryi were negatively associated with tidal amplitude (Fig. 5, Table 3). We found no evidence that wind speed affected recruitment (Table 3).

LEV played an important role for 6 taxa. Temperature was the only variable to be identified by hierarchical partitioning for all 6 taxa and to be included in all significant models (Table 3). The sign of the association with temperature differed among taxa, with some taxa exhibiting positive associations (Sparisoma spp., Scarus spp., Thalassoma bifasciatum) and some exhibiting negative ones (Stegastes partitus, Pseudogramma gregoryi, Gnatholepis thompsoni; Fig. 5, Table 3). We also found consistent evidence of an important role of the NBC ring passage for 4 taxa, but these taxa were associated in different ways with different aspects of the ring passage. Sparisoma spp. and P. gregoryi exhibited positive and negative associations, respectively, with chlorophyll a (Fig. 5, Table 3). Scarus spp. and $T$. bifasciatum exhibited positive and negative associations, respectively, with nLw(555 nm) (Fig. 5, Table 3). Finally, cloud cover was also associated with recruitment, positively in $P$. gregoryi and negatively in $G$. thompsoni (Fig. 5, Table 3).

There were some discrepancies between methods in the importance of individual variables for some taxa. For Sparisoma spp., Stegastes partitus and Gnatholepis thompsoni, the ranking of the variables in importance based on the independent contribution (as inferred from hierarchical partitioning) was consistent with the standardized partial regression coefficients, as inferred from the $C(\mathrm{p})$ models. For Scarus spp. and Thalassoma bifasciatum, the 2 methods agreed in the ranking of the most important variable, but exhibited discrepancies in the lower ranking variables. For Pseudogramma gregoryi, the methods were inconsistent, only agreeing on the lowest ranking variable (Table 3). Nevertheless, both methods were consistent in identifying the highest ranking variable for all taxa except P. gregoryi. For Sparisoma spp., Scarus spp., T. bifasciatum and G. thompsoni, the highest ranking variable was a LEV (temperature or nLw[555 nm]; Table 3). For S. partitus, the highest ranking variable was a SEV (new moon; Table 3). For P. gregoryi, the highest ranking variable identified by 


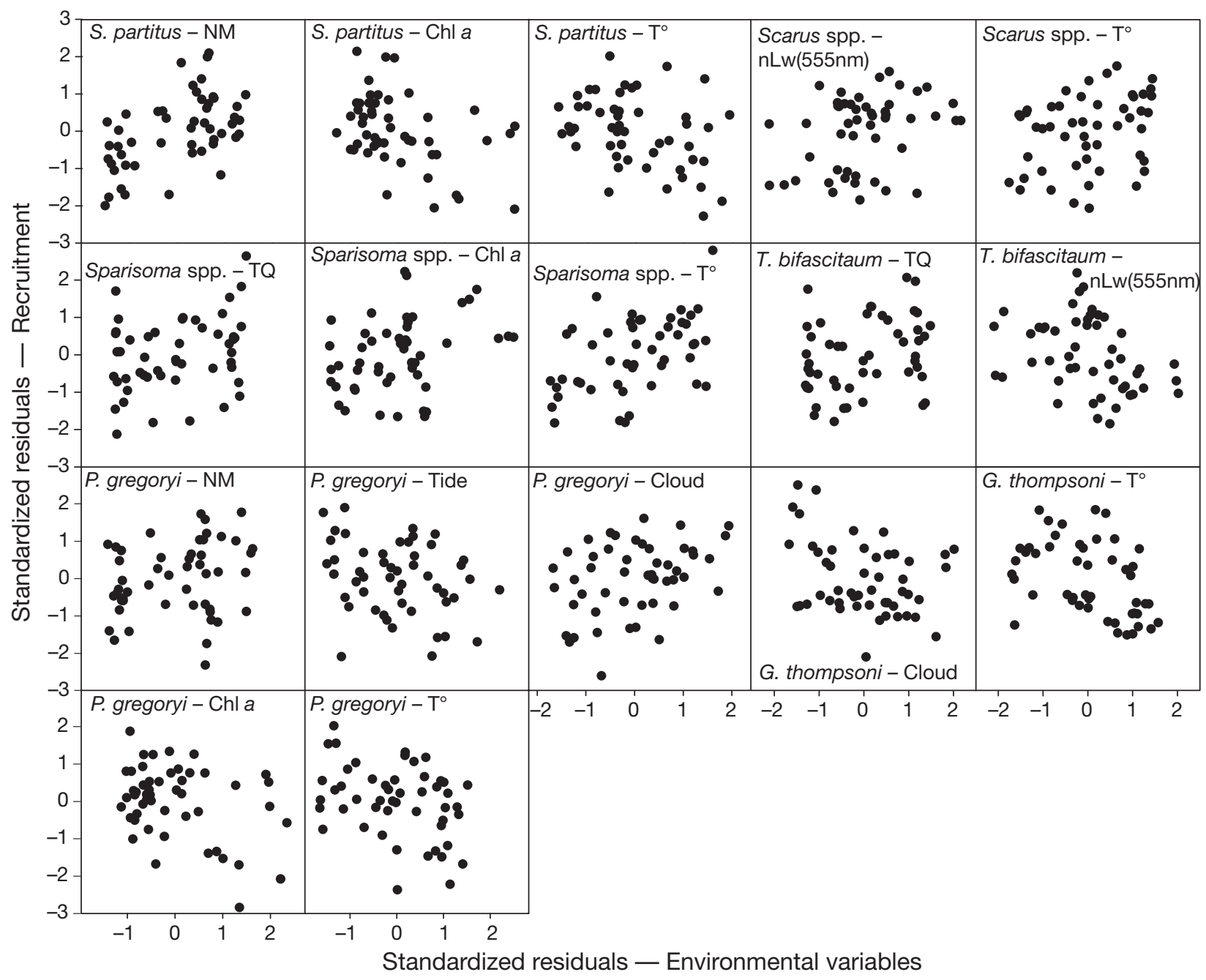

Fig. 5. Scatterplots of associations between recruitment and the environmental variables that were identified as important by hierarchical partitioning and the Mallow's $C(\mathrm{p})$ model selection. Data represent partial standardized residuals of recruitment (vertical axis) and a given environmental variable (horizontal axis; see Fig. 4 for abbreviations) after controlling for the effect of all other variables that were retained in the best Mallow's $C(p)$ model

hierarchical partitioning was a SEV (tidal amplitude), whereas the one identified in the $C(p)$ model selection was a LEV (chlorophyll $a$; Table 3). Finally, we found no significant evidence of strongly influential observations for any of the $C(\mathrm{p})$ models retained, as measured by Cook's distance.

\section{DISCUSSION}

The present study has demonstrated diversity in temporal patterns of concurrent recruitment among 8 taxa of coral reef fishes over a 17 mo period and has identified environmental factors associated with such patterns at temporal scales relevant to the population dynamics of many coral reef fishes (Robertson \& Kauf- mann 1998). There is evidence for considerable diversity among taxa in environmental associations as well as in the relative roles of SEV and LEV.

\section{Variables associated with settlement}

SEV played an important role for 5 taxa through the lunar darkness cycle and the tidal amplitude cycle. Lunar and tidal patterns of settlement are common in coral reef fishes (e.g. Robertson 1992, Lozano \& Zapata 2003). In Barbados, several of the species examined in this study (i.e. Stegastes partitus, Sparisoma viride, Thalassoma bifasciatum, Coryphopterus glaucofraenum and Gnatholepis thompsoni) are known to settle predominantly around the third quarter moon (Spo- 
naugle \& Cowen 1994, 1996a,b, 1997), although other species settle around the new moon (Labelle \& Nursall 1992, Sponaugle \& Cowen 1996a, 1997). The lunar recruitment patterns identified in our study are consistent with this previous work, indicating that both third quarter and new moon patterns occur in Barbados. The lack of a lunar effect for Coryphopterus spp. could be the result of different lunar patterns for 2 species that we could not discriminate within this taxon, whereas for $G$. thompsoni, low catches during much of the year may have reduced our ability to detect lunar patterns. Additionally, the loss of resolution associated with $10 \mathrm{~d}$ mean values may have precluded detecting lunar patterns for taxa exhibiting very high variability around the lunar peak (e.g. C. glaucofraenum; Sponaugle \& Cowen 1994). For $S$. partitus, the new moon pattern found in our study contrasts with the third quarter moon pattern identified by Sponaugle \& Cowen (1996a). Differences between studies in sampling resolution and duration make comparisons difficult. Sponaugle \& Cowen (1996a) sampled at a finer temporal scale (i.e. days) than we did, but examined recruitment over a shorter period of the year (March to May). Our study involved $10 \mathrm{~d}$ averages but spanned 17 mo and thus incorporated a wider range of oceanographic conditions such as seasonal variation in the tidal amplitude cycle, which could interact with the lunar cycle to shift lunar patterns in recruitment (Sponaugle \& Cowen 1997).

The differences among taxa in the lunar pattern may reflect several processes. For taxa with short and invariant larval durations such as Stegastes partitus ( $\sim 30 \mathrm{~d})$, recruitment may simply reflect lunar patterns in the timing of spawning (e.g. Robertson et al. 1988). Daily spawning of $S$. partitus in Barbados peaks around the new moon (Fig. 2 in Cowen 2002), which is consistent with lunar peaks in recruitment 30 d later. Strong associations between spawning and recruitment at lunar scales are less likely for taxa with longer and more variable larval durations, such as Pseudogramma gregoryi, Sparisoma spp. and Thalassoma bifasciatum. For these taxa, lunar patterns likely reflect the interaction between flexibility in larval duration, selection for settlement when darker nights reduce vulnerability to visual predators, and degree of dependence on tidally associated onshore movement or retention (Sponaugle \& Cowen 1997, Reyns \& Sponaugle 1999). Further, the nature of this interaction might be modified by NBC ring passage, resulting in a shift in lunar patterns (Sponaugle \& Pinkard 2004a). Although it is likely that both tidal amplitude and the lunar darkness cycle, either alone or jointly, influence recruitment, it is difficult to separate their exact roles because they are tightly coupled throughout much of the year in Barbados (Sponaugle \& Cowen 1997). Nevertheless, the negative associations of Scarus spp. and P. gregoryi with tidal amplitude, after controlling for all other variables and despite the loss of temporal resolution associated with our $10 \mathrm{~d}$ averages, suggest that tidal amplitude plays a role independently of lunar darkness. It also indicates that sampling more frequently might have increased detection of tidal amplitude effects across taxa.

Although studies elsewhere have found positive associations between reef fish larval delivery and winds (e.g. Shenker et al. 1993, Milicich 1994), wind did not appear to vary enough to be important in our study. The $10 \mathrm{~d}$ average winds were consistently weak and offshore. It is possible that the loss of resolution in our $10 \mathrm{~d}$ averages might have made it difficult to detect a role. However, using a finer temporal resolution (days) in Barbados, Sponaugle \& Cowen (1996a) were unable to resolve a role of wind on fish larval supply, whereas Reyns \& Sponaugle (1999) found only weak associations between wind and the supply of crustacean postlarvae. Thus, wind does not appear to be an important determinant of variation in the recruitment of reef organisms to the west coast of Barbados.

\section{Variables associated with pelagic larval life}

LEV were associated with recruitment in 6 taxa. Temperature was associated with all 6, suggesting a particularly important role. Differences across taxa in the sign of the association with temperature might reflect a differential effect of temperature on larval survival. Temperature increases metabolic rates and food consumption in fishes up to an optimum (Wootton 1998) and is generally positively associated with larval growth rates and negatively associated with age at metamorphosis in both temperate and tropical fishes (Benoît et al. 2000). High growth rates could increase larval survival by reducing both the period of vulnerability to particular size-limited predators (Ware 1975) and the total time spent in the plankton (Houde 1987). However, a positive association between growth rates and temperature requires that food intake meets metabolic demands. A limited food supply may reverse this relationship (Anderson 1988). The interaction between temperature and food supply may explain the domeshaped relationship between growth rates and temperature found in some temperate species under natural conditions when food is likely to be limiting (e.g. Buckley et al. 2004). Because larval fish species differ in metabolic demands (e.g. Parra \& Yúfera 2001) and in larval traits such as swimming and perceptual capabilities that influence feeding success (Blaxter 1986, Job \& Bellwood 2000, Fisher et al. 2005), a differential effect of temperature on recruitment could reflect dif- 
ferences in the ability of larvae to meet metabolic demands. Such a differential effect may have been exacerbated by the relatively high temperatures observed during our study, with $10 \mathrm{~d}$ averages varying between 27.0 and $30.1^{\circ} \mathrm{C}$ (Fig. 3), whereas year-round studies in the 1980s (Borstad 1982a) and 1990s (Sponaugle \& Pinkard 2004b) reported seasonal temperatures varying between 25.0 and $28.8^{\circ} \mathrm{C}$.

The importance of other LEV varied among taxa. Because salinity and chlorophyll a were very tightly linked, they likely signaled the passage of NBC lowsalinity intrusions, i.e. salinity $<34.5$ psu (Kelly et al. 2000), given that salinity was not positively associated with local rainfall ( $\mathrm{H}$. Vallès unpubl. data). The increase in chlorophyll a during NBC ring passage is most likely due to increases in productivity potentially resulting from nutrient upwelling (Ryther et al. 1967). The difference in the sign of the association between chlorophyll a and recruitment for Pseudogramma gregoryi and Sparisoma spp. might reflect the outcome of several processes tightly associated with the NBC lowsalinity intrusions. It is unlikely that larval osmotic stress was an important factor because of the small variation in salinity ( 32 to $36 \mathrm{psu}$ ). On the other hand, changes in the zooplankton community and in hydrodynamic processes are likely to have been important.

The NBC ring passage changes the abundance and composition of the zooplankton community in the waters surrounding Barbados (Kidd \& Sander 1979, Borstad 1982b). The difference between Sparisoma spp. and Pseudogramma gregoryi in the sign of the association with ring passage might reflect differences in availability of suitable food for each taxon. Leis (1991) argued that there is substantial specialization in the diet of reef fish larvae. Sponaugle \& Pinkard (2004b) found that Thalassoma bifasciatum larvae exposed to the NBC rings grew more slowly than larvae not exposed to the rings, suggesting lower feeding rates during ring presence, perhaps because of scarcity of suitable food for this species. Changes in zooplankton composition may also affect predation rates on the 2 taxa differently. Predators are likely to be abundant and diverse throughout the entire pelagic stage and include many invertebrates and other fishes (Bailey \& Houde 1989). The larger size of $P$. gregoryi may increase vulnerability to larger fish predators (Leggett \& Deblois 1994), overriding advantages usually associated with increased larval size (Miller et al. 1988). In addition, the abundance of alternative prey may also have differed between NBC ring and non-ring events, which could also have influenced predation risk (Heath 1992).

The low-salinity intrusions signaled by chlorophyll $a$ may also have influenced larval near-shore retention. Cowen et al. (2003) found that 1 NBC ring resulted in higher water retention rates near the west coast of Bar- bados, although another ring had the opposite effect. The ring event with higher water retention was followed by a large recruitment pulse of Thalassoma bifasciatum, possibly because it increased larval retention (Cowen et al. 2003, Sponaugle \& Pinkard 2004b). NBC rings are vertically structured (Kelly et al. 2000) and induce changes in the vertical distribution of larvae (Cowen et al. 2003, Paris \& Cowen 2004) that may affect larval retention or advection. Because coral reef fish larvae exhibit taxon-specific differences in vertical distribution (Leis 1991, Cowen 2002), the degree of retention during ring passage may differ among taxa as a consequence of the changes in the vertical distribution of larvae in relation to peak onshore flow (Cowen \& Castro 1994, Paris \& Cowen 2004).

The associations between cloud cover or $\mathrm{nLw}(555 \mathrm{~nm})$ and recruitment of 4 taxa may reflect effects of light intensity on larval feeding and/or predation rates, given the importance of vision in the predator-prey dynamics of larvae of teleost fishes (Hunter 1981, Blaxter 1986). The inclusion of nLw(555 nm) in our analyses was justified because $\mathrm{nLw}(555 \mathrm{~nm})$ appeared to reflect aspects of the NBC ring passage that differed from changes in chlorophyll $a$ at fine temporal scales. Long periods of heavy cloud cover or turbidity associated with the NBC ring passage (i.e. $\mathrm{nLw}[555 \mathrm{~nm}]$ ) might have resulted in light-intensity decreases within the range that affects the light-regulated perceptual capabilities of larvae and their predators, at least at some water depths and times of day. For example, Gallego et al. (1996) found that natural levels of light intensity associated with cloud cover affected larval growth rates of herring, likely through feeding. Such an effect of light on foraging would also apply to visual predators of larvae such as other fishes (Hunter 1981). Larval fishes differ in the minimum light intensity required to initiate feeding, indicating different light-regulated perceptual capabilities (Blaxter 1986, Job \& Bellwood 2000), so the effects of changes in the perceptual environment could vary among taxa.

It is difficult to exclude an effect of LEV for which we failed to find associations with recruitment. Given the highly patchy and dynamic nature of the marine environment over multiple scales (Haury et al. 1978, Denman \& Gargett 1983), interactions among factors could have obscured such associations. For example, Sponaugle et al. (2006) found a significant relationship between recruitment and temperature for Thalassoma bifasciatum, but only when data collected during the presence of meso-scale eddies were removed from the analysis. Our preliminary analyses indicated that including interaction terms in our models provided negligible increases in explanatory power, suggesting that any important interactions would be more likely to have involved unmeasured factors. This warrants caution in the interpretation of the lack of associations. Non-linear associations between re- 
cruitment and measured factors (e.g. Dixon et al. 1999) might have also contributed to obscure associations, although our preliminary analyses and inspection of residual scatterplots (Fig. 5) did not suggest that this was a major problem. Not having accurate estimates of larval duration might also have contributed to weaken associations. This would be the case if there was substantial cohort (temporal) variability in larval duration (e.g. Bay et al. 2006), particularly in the taxa with very flexible larval durations (e.g. Gnatholepis thompsoni; Sponaugle \& Cowen 1994), so that our rough estimates of larval duration considerably over- or under-estimated actual larval duration over time. Moreover, having more than 1 species represented in some of our generic taxa might also have weakened recruitment-environment associations if the different species within genera exhibit different environmental responses. This might explain the lack of environmental associations for Coryphopterus spp., the only 1 of our 3 generic taxa for which at least 2 species were confirmed using DNA analysis (see Table 1). In contrast, it is unlikely that such pooling within genera could have produced artifactual associations.

Some of the environmental associations between recruitment and LEV may reflect environmental influences on reproductive output (e.g. seasonal variability in spawning intensity; Hunt von Herbing \& Hunte 1991). We cannot separate environmental influences on spawning from influences on planktonic larvae without independent data on spawning. Nevertheless, because planktonic processes greatly enhance variability in recruitment relative to that expected from reproductive effort in coral reef fishes (Robertson et al. 1988, 1993), it is most likely that the environmental associations reported here predominantly reflect planktonic influences on larvae.

\section{Relative importance of SEV and LEV factors}

Across taxa, the most important variable was not consistently LEV or SEV, although a LEV ranked highest for most taxa. The differences in the importance of LEV and SEV for the 2 most abundant taxa, Sparisoma spp. and Stegastes partitus, suggest that whichever set of variables is considered more important is not an artifact of our methods or of low catches. Instead, the variables likely reflect aspects of the biology of the different taxa that ultimately influence recruitment. One such aspect may be the combination of spawning timing and larval duration, reinforcing the lunar signal for $S$. partitus, but not for Sparisoma spp. Other aspects may reflect physiological adaptations to larval duration. Sparisoma spp. spends twice as much time in the plankton as does S. partitus and exhibits comparatively higher variability in larval duration (Sponaugle \& Cowen 1996b, Robertson et al. 2006). This implies that Sparisoma spp. will likely experience a wider range of environmental variability in the pelagic than $S$. partitus, including variability in temperature and food availability. High plasticity in growth rates associated with variable pelagic duration would represent an adaptive advantage for such taxa, as has been suggested for Thalassoma bifasciatum (Searcy \& Sponaugle 2000). Because larvae with plastic growth rates might tolerate a wider range of variation in $L E V$, relationships between recruitment and such factors could be stronger for these taxa and easier to detect in a noisy environment. Importantly, this suggests that the environmental variables that best predict recruitment can operate at different scales of temporal variation across taxa, which has implications for monitoring recruitment. For example, long-term studies with moderate to low sampling frequency may suffice to capture the bulk of variation in recruitment driven by the environment for Sparisoma spp., whereas a finer sampling resolution will be necessary for $S$. partitus.

Our finding that LEV appeared to be important in determining recruitment variability within and among taxa is consistent with the few other field studies that have examined LEV in the recruitment of coral reef fishes (Wilson \& Meekan 2001, 2002, Bergenius et al. 2005, Sponaugle et al. 2006). The importance of LEV probably reflects their cumulative effect on growth and mortality rates throughout the larval stage. In a modeling study, Houde (1989) showed that very small changes in growth or mortality rates during the larval stage, to which LEV likely contribute most, have greater impact on the magnitude of recruitment than episodic losses of eggs or larvae, to which SEV could contribute through transportrelated processes.

\section{Consistency between hierarchical partitioning and model selection}

Hierarchical partitioning and the model selection approach were generally consistent in the variables identified as important, which implies that the most meaningful variables were identified for each taxon. There were, however, some discrepancies between methods in the variables retained and in the relative importance of these variables. This highlights the sensitivity of some of our results to a given method and underscores the usefulness of combining both approaches to yield robust conclusions (Mac Nally 2000). Thus, for Lythrypnus nesiotes and Coryphopterus spp., the lack of significance and low explanatory power of the models retained suggested that the findings of hierarchical partitioning were not meaningful; on the other hand, it also suggested that the environmental associations found for the other taxa are not an artifact of our methods. 


\section{CONCLUSION}

Our findings support the emerging view that factors operating throughout the larval stage play a role as important for coral reef fishes as they do for the species that are the focus of temperate fisheries. This warrants further research into the influence of the environment on the early life-history traits in a diversity of coral reef fishes. Furthermore, our study has revealed substantial diversity across taxa in the effect of a temporally variable planktonic environment on recruitment, which likely contributes to explain the differences in temporal patterns observed here among taxa. This diversity in environmental effects and temporal recruitment patterns is consistent with models of species co-existence based on the storage effect (Warner \& Chesson 1985; for further details, see Vallès 2008) and has implications for effective monitoring of recruitment. Finally, because this diversity in environmental effects occurred during a period of sustained warm sea temperatures, it also suggests that the effects of climate change on early life-history traits, and subsequent recruitment (see review in Munday et al. 2008) will differ among coral reef fishes.

Acknowledgements. We thank A. Desrochers, M. Richardson, A. C. Breault, K. Baldwin, R. Goodridge, R. Roach, D. Roche, L. Robertson, F. Hinds, A. Griffin, C. Bissada, D. Perez and the many other volunteer divers who provided assistance in the field. K. Turgeon and S. Morgan provided comments on an earlier version of this manuscript. S. Burton kindly facilitated the data from the Caribbean Center of Hydrology and Meteorology. We particularly thank B. and M. Selliah and J. Horrocks for generous room and/or board support. We thank R. Haynes, B. Downey and the staff of Bellairs Research Institute of McGill University for logistical support. We are particularly indebted to B. Victor for identification and ageing of specimens and to R. Mahon and H. Oxenford of the University of the West Indies (UWI) for allowing us to use UWI-CERMES facilities and a boat when needed. This research was partially funded by UWI grants to W.H. and a Natural Sciences and Engineering Research Council of Canada Discovery grant to D.L.K. Additional support came from a PADI-AWARE project grant and a Small Scheme grant from the Fisheries Society of the British Isles to H.V. Waddell Aquatics Dive Shop, Montreal, provided a substantial discount on diving equipment.

\section{LITERATURE CITED}

Anderson JT (1988) A review of size dependent survival during pre-recruit stages of fishes in relation to recruitment. J Northwest Atl Fish Sci 8:55-66

Bailey KM, Houde ED (1989) Predation on eggs and larvae of marine fishes and the recruitment problem. Adv Mar Biol 25:1-83

Bay LK, Buechler K, Gagliano M, Caley MJ (2006) Intraspecific variation in the pelagic larval duration of tropical reef fishes. J Fish Biol 68:1206-1214

Beaugrand G, Brander KM, Lindley JA, Souissi S, Reid PC (2003) Plankton effect on cod recruitment in the North Sea. Nature 426:661-664
Benoît HP, Pepin P, Brown JA (2000) Patterns of metamorphic age and length in marine fishes, from individuals to taxa. Can J Fish Aquat Sci 57:856-869

Bergenius MAJ, Meekan MG, Robertson DR, McCormick MI (2002) Larval growth predicts the recruitment success of a coral reef fish. Oecologia 131:521-525

> Bergenius MAJ, McCormick MI, Meekan MG, Robertson DR (2005) Environmental influences on larval duration, growth and magnitude of settlement of a coral reef fish. Mar Biol 147:291-300

Blaxter JHS (1986) Development of sense organs and behaviour of teleost larvae with special reference to feeding and predator avoidance. Trans Am Fish Soc 115: 98-114

Borstad GA (1982a) The influence of the meandering Guiana Current and Amazon River discharge on surface salinity near Barbados. J Mar Res 40:421-434

Borstad GA (1982b) The influence of the meandering Guiana Current on surface conditions near Barbados - temporal variations of Trichodesmium (Cyanophyta) and other plankton. J Mar Res 40:435-451

Buckley LJ, Caldarone EM, Lough RG (2004) Optimum temperature and food-limited growth of larval Atlantic cod (Gadus morhua) and haddock (Melanogrammus aeglefinus) on Georges Bank. Fish Oceanogr 13:134-140

> Chevan A, Sutherland M (1991) Hierarchical partitioning. Am Stat 45:90-96

Cowen RK (2002) Larval dispersal and retention consequences for population connectivity. In: Sale PF (ed) Coral reef fishes: dynamics and diversity in a complex ecosystem. Academic Press, San Diego, CA, p 149-170

Cowen RK, Castro LR (1994) Relation of coral-reef fish larval distributions to island scale circulation around Barbados, West Indies. Bull Mar Sci 54:228-244

Cowen RK, Sponaugle S (1997) Relationships between early life history traits and recruitment among coral reef fishes. In: Chambers C, Trippel EA (eds) Early life history and recruitment in fish populations. Chapman \& Hall, London, p 423-444

Cowen RK, Sponaugle S, Paris CB, Fortuna JL, Lwiza KMM, Dorsey S (2003) Impact of North Brazil Current rings on local circulation and coral reef fish recruitment to Barbados, West Indies. In: Goni GJ, Malanotte-Rizzoli P (eds) Interhemispheric water exchange in the Atlantic Ocean. Elsevier, Amsterdam, p 443-462

> Cowen RK, Paris CB, Srinivasan A (2006) Scaling of connectivity in marine populations. Science 311:522-527

Denman KL, Gargett AE (1983) Time and space scales of vertical mixing and advection of phytoplankton in the upper ocean. Limnol Oceanogr 28:801-815

> Dixon PA, Milicich MJ, Sugihara G (1999) Episodic fluctuations in larval supply. Science 283:1528-1530

> Fisher R, Leis JM, Clark DL, Wilson SK (2005) Critical swimming speeds of late-stage coral reef fish larvae: variation within species, among species and between locations. Mar Biol 147:1201-1212

Fortin MJ, Dale M (2005) Spatial analysis: a guide for ecologists. Cambridge University Press, Cambridge

Fratantoni DM, Glickson DA (2002) North Brazil Current Ring generation and evolution observed with SeaWiFS. J Phys Oceanogr 32:1058-1074

> Fukuhara O (1990) Effects of temperature on yolk utilization, initial growth, and behaviour of unfed marine fish-larvae. Mar Biol 106:169-174

> Gallego A, Heath MR, McKenzie E, Cargill LH (1996) Environmentally induced short-term variability in the growth rates of larval herring. Mar Ecol Prog Ser 137:11-23

Goni GJ, Johns WE (2001) A census of North Brazil Current 
Rings observed from TOPEX/POSEIDON altimetry: 19921998. Geophys Res Lett 28:1-4

Green BS, Fisher R (2004) Temperature influences swimming speed, growth and larval duration in coral reef fish larvae. J Exp Mar Biol Ecol 299:115-132

Haury LR, McGowan JA, Wiebe PH (1978) Patterns and processes in the time-space scales of plankton distributions. In: Steele JH (ed) Spatial pattern in plankton communities. Plenum Press, New York, p 277-328

Heath MR (1992) Field investigations of the early life stages of marine fish. Adv Mar Biol 28:1-174

Hjort J (1914) Fluctuations in the great fisheries of northern Europe. Rapp P-V Reun Cons Int Explor Mer 20:1-228

Holm S (1979) A simple sequentially rejective multiple test procedure. Scand J Stat 6:65-70

Houde ED (1987) Fish early life dynamics and recruitment variability. Am Fish Soc Symp 2:17-29

Houde ED (1989) Subtleties and episodes in the early life of fishes. J Fish Biol 35:29-38

Hunt von Herbing I, Hunte W (1991) Spawning and recruitment of the bluehead wrasse Thalassoma bifasciatum in Barbados, West-Indies. Mar Ecol Prog Ser 72:49-58

Hunter JR (1981) Feeding ecology and predation of marine fish larvae. In: Lasker R (ed) Marine fish larvae; morphology, ecology and relation to fisheries. University of Washington Press, Seattle, WA, p 33-77

Job SD, Bellwood DR (2000) Light sensitivity in larval fishes: implications for vertical zonation in the pelagic zone. Limnol Oceanogr 45:362-371

Kelly PS, Lwiza KMM, Cowen RK, Goni GJ (2000) Lowsalinity pools at Barbados, West Indies: their origin, frequency, and variability. J Geophys Res 105:19699-19708

Kidd R, Sander F (1979) Influence of Amazon River discharge on the marine production system off Barbados, West Indies. J Mar Res 37:669-681

Kingsford MJ (2001) Diel patterns of abundance of presettlement reef fishes and pelagic larvae on a coral reef. Mar Biol 138:853-867

Kingsford MJ, Wolanski E, Choat JH (1991) Influence of tidally induced fronts and langmuir circulations on distribution and movements of presettlement fishes around a coral reef. Mar Biol 109:167-180

Kutner MH, Nachtsheim CJ, Neter J (2004) Applied linear regression models, 4th edn. McGraw-Hill Irwin, New York

Labelle M, Nursall JR (1992) Population biology of the redlip blenny, Ophioblennius atlanticus macclurei (Sylvester) in Barbados. Bull Mar Sci 50:186-204

Legendre P, Legendre L (1998) Numerical ecology, 2nd edn. Elsevier, Amsterdam

Leggett WC, Deblois E (1994) Recruitment in marine fishes: Is it regulated by starvation and predation in the egg and larval stages? Neth J Sea Res 32:119-134

Leis JM (1991) The pelagic stage of reef fishes: the larval biology of coral reef fishes. In: Sale PF (ed) The ecology of fishes on coral reefs. Academic Press, San Diego, CA, p $183-230$

Leis JM, McCormick MI (2002) The biology, behavior and ecology of the pelagic, larval stage of coral reef fishes. In: Sale PF (ed) Coral reef fishes: dynamics and diversity in a complex ecosystem. Academic Press, San Diego, CA, p 171-199

Lozano S, Zapata FA (2003) Short-term temporal patterns of early recruitment of coral reef fishes in the tropical eastern Pacific. Mar Biol 142:399-409

Mac Nally R (1996) Hierarchical partitioning as an interpretative tool in multivariate interference. Aust J Ecol 21: $224-228$
Mac Nally R (2000) Regression and model-building in conservation biology, biogeography and ecology: the distinction between - and reconciliation of - 'predictive' and 'explanatory' models. Biodivers Conserv 9:655-671

- McCormick MI, Molony BW (1995) Influence of water temperature during the larval stage on size, age and body condition of a tropical reef fish at settlement. Mar Ecol Prog Ser 118:59-68

> Meekan MG, Carleton JH, McKinnon AD, Flynn K, Furnas M (2003) What determines the growth of tropical reef fish larvae in the plankton: food or temperature? Mar Ecol Prog Ser 256:193-204

> Milicich MJ (1994) Dynamic coupling of reef fish replenishment and oceanographic processes. Mar Ecol Prog Ser 110:135-144

Miller TJ, Crowder LB, Rice JA, Marschall EA (1988) Larval size and recruitment mechanisms in fishes: toward a conceptual framework. Can J Fish Aquat Sci 45:1657-1670

Muller-Karger FE, McClain CR, Richardson PL (1988) The dispersal of the Amazon's water. Nature 333:56-59

Munday PL, Jones GP, Pratchett MS, Williams AJ (2008) Climate change and the future of coral reef fishes. Fish Fish 9:261-285

Novo EMM, Hansom JD, Curran PJ (1989) The effect of viewing geometry and wavelength on the relationship between reflectance and suspended sediment concentration. Int J Remote Sens 10:1357-1372

Otero MP, Siegel DA (2004) Spatial and temporal characteristics of sediment plumes and phytoplankton blooms in the Santa Barbara Channel. Deep Sea Res II 51:1129-1149

Paris CB, Cowen RK (2004) Direct evidence of a biophysical retention mechanism for coral reef fish larvae. Limnol Oceanogr 49:1964-1979

> Parra G, Yúfera M (2001) Comparative energetics during early development of two marine fish species, Solea senegalensis (Kaup) and Sparus aurata (L.). J Exp Biol 204: $2175-2183$

> Pyper BJ, Peterman RM (1998) Comparison of methods to account for autocorrelation in correlation analyses of fish data. Can J Fish Aquat Sci 55:2127-2140

$>$ Reyns N, Sponaugle S (1999) Patterns and processes of brachyuran crab settlement to Caribbean coral reefs. Mar Ecol Prog Ser 185:155-170

Robertson DR (1992) Patterns of lunar settlement and early recruitment in Caribbean reef fishes at Panama. Mar Biol 114:527-537

> Robertson DR, Kaufmann KC (1998) Assessing early recruitment dynamics and its demographic consequences among tropical reef fishes: accommodating variation in recruitment seasonality and longevity. Aust J Ecol 23:226-233

Robertson DR, Green GD, Victor CB (1988) Temporal coupling of production and recruitment of larvae of a Caribbean reef fish. Ecology 69:370-381

Robertson DR, Schober UM, Brawn JD (1993) Comparative variation in spawning output and juvenile recruitment of some Caribbean reef fishes. Mar Ecol Prog Ser 94:105-113

Robertson DR, Karg F, Leao de Moura R, Victor BC, Bernardi G (2006) Mechanisms of speciation and faunal enrichment in Atlantic parrotfishes. Mol Phylogenet Evol 40:795-807

Ryther JH, Menzel DW, Corwin N (1967) Influence of the Amazon River outflow on the ecology of the western tropical Atlantic I. Hydrography and nutrient chemistry. J Mar Res 25:69-83

> Searcy SP, Sponaugle S (2000) Variable larval growth in a coral reef fish. Mar Ecol Prog Ser 206:213-226

> Shenker JM, Maddox ED, Wishinski E, Pearl A, Thorrold SR, Smith N (1993) Onshore transport of settlement-stage 
Nassau grouper Epinephelus striatus and other fishes in Exuma Sound, Bahamas. Mar Ecol Prog Ser 98:31-43

Sponaugle S, Cowen RK (1994) Larval durations and recruitment patterns of two Caribbean gobies (Gobiidae) - contrasting early-life histories in demersal spawners. Mar Biol 120:133-143

Sponaugle S, Cowen RK (1996a) Nearshore patterns of coral reef fish larval supply to Barbados, West Indies. Mar Ecol Prog Ser 133:13-28

Sponaugle S, Cowen RK (1996b) Larval supply and patterns of recruitment for two Caribbean reef fishes, Stegastes partitus and Acanthurus bahianus. Mar Freshw Res 47: 433-447

Sponaugle S, Cowen RK (1997) Early life history traits and recruitment patterns of Caribbean wrasses (Labridae). Ecol Monogr 67:177-202

Sponaugle S, Pinkard D (2004a) Lunar cyclic population replenishment of a coral reef fish: shifting patterns following oceanic events. Mar Ecol Prog Ser 267:267-280

Sponaugle S, Pinkard DR (2004b) Impact of variable pelagic environments on natural larval growth and recruitment of the reef fish Thalassoma bifasciatum. J Fish Biol 64:34-54

Sponaugle S, Grorud-Colvert K, Pinkard D (2006) Temperature-mediated variation in early life history traits and recruitment success of the coral reef fish Thalassoma bifasciatum in the Florida Keys. Mar Ecol Prog Ser 308:1-15

ter Braak CJF, Smilauer P (2002) Canoco reference manual and CanoDraw for Windows user's guide: software for canonical community ordination (Version 4.5). Microcomputer Power, Ithaca, NY

Vallès H (2008) Spatial and temporal patterns of recruitment

Editorial responsibility: Jon Hare,

Narragansett, Rhode Island, USA of coral reef fishes to the west coast of Barbados (West Indies): an approach using a novel standard unit of settlement habitat. PhD thesis, McGill University, Montreal

> Vallès H, Kramer DL, Hunte W (2006) A standard unit for monitoring recruitment of fishes to coral rubble. J Exp Mar Biol Ecol 336:171-183

Vallès H, Kramer DL, Hunte W (2008) Temporal and spatial patterns in the recruitment of coral-reef fishes in Barbados. Mar Ecol Prog Ser 363:257-272

Walsh CJ, Mac Nally R (2003) The hier.part Package Version 0.1-1. Hierarchical partitioning. Available at: http://cran. r-project.org/

Ware DM (1975) Relation between egg size, growth, and natural mortality of larval fish. J Fish Res Board Can 32: 2503-2512

Warner RR, Chesson PL (1985) Coexistence mediated by recruitment fluctuations - a field guide to the storage effect. Am Nat 125:769-787

Watanabe WO, Ellis SC, Ellis EP, Feeley MW (1999) Temperature effects on eggs and yolk sac larvae of the summer flounder at different salinities. N Am J Aquac 61:267-277

Wilson DT, Meekan MG (2001) Environmental influences on patterns of larval replenishment in coral reef fishes. Mar Ecol Prog Ser 222:197-208

Wilson DT, Meekan MG (2002) Growth-related advantages for survival to the point of replenishment in the coral reef fish Stegastes partitus (Pomacentridae). Mar Ecol Prog Ser 231:247-260

Wootton RJ (1998) Ecology of teleost fishes, 2nd edn. Kluwer Academic Publishers, Dordrecht

Submitted: June 12, 2008; Accepted: December 10, 2008

Proofs received from author(s): March 18, 2009 